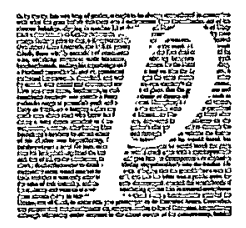

\title{
Adaptación, interpretación, escritura: los horizontes del texto literario. La traducción: también un problema de filosofía
}

\author{
Ana María Martínez de la Escalera \\ Instituto de Investigaciones Filológicas \\ Universidad Nacional Autónoma de México \\ Todos los caminos del pensar llevan, de una forma desacostumbrada, a \\ través del lenguaje. \\ Martin Heidegger
}

- Hay aún algo que decir, algo que no ha sido dicho, sobre la traducción? ¿Algo que no sólo explicase técnicamente lo que la traducción es, sino algo que vinculándola con otros haceres humanos, con la esencia del hacer humano incluso, nos permitiese dar cuenta de lo que somos o aspiramos a ser? Me refiero a si habría algo que decir sobre la traducción que nos condujera más allá de las respuestas de la moderna ontología, lamentablemente presa de un cierto romanticismo del espíritu.

Regresemos al epígrafe de estas consideraciones: el camino del pensar -aquello por lo que nos tornamos humanos-, escribió Heidegger, no puede emprenderse si no es comenzando por el lenguaje. Esta fórmula les sería muy familiar a muchos teóricos del movimiento romántico. Von Kleist, por ejemplo, haría referencia a "la paulatina 
elaboración del pensamiento al hablar" (1995, 175-80). Para los románticos la poesia no debía ir en busca de cosas sino de palabras, nombres de cosas.

Aunque nos sintamos con ánimo para concordar con el poeta alemán, es preciso notar que reducir por completo el pensamiento de lo que es a la lengua, presenta problemas sobre los que Nietzsche habria de advertirnos. Uno de ellos es, por supuesto, la posibilidad absoluta de la traducción. Tras notar que "dejamos de pensar si nos negamos a hacerlo bajo la coerción del lenguaje" (Fragmentos póstumos 1886-1887), Nietzsche declarará que "toda palabra es un prejuicio" y que "(teme) que no nos quitaremos a Dios de encima mientras creamos en la gramática." Aún más, recomendará al filósofo que no caiga "preso en las redes del lenguaje" puesto que "(e)n el lenguaje está escondida una mitología filosófica que vuelve a salir a cada momento, por cauto que se quiera ser" (Valverde 1994). Pero, ¿cómo escapar entonces de las redes del lenguaje? Es decir, ¿cómo pensar de forma desacostumbrada, como decía Heidegger, cómo pensar lo nuevo desde lo usual, lo de siempre? Nietzsche estaba convencido de que no podría hacerse apelando simplemente a la vigilancia de la razón -por la que él sentía desconfianza - a "la verdad," a "la vida," al cogito o a las "cosas mismas" puesto que éstos no son sino gastados mitologemas que han agotado sus fuerzas expresivas para decir de otra manera, para decir lo nuevo. Él creía que un acto de gran desasimiento, un pathos de la distancia debia interponerse entre el pensador y su lengua, su patria, su religión. Lo que el filósofo alemán tenía en mente como modelo de referencia era ese espacio crítico que se abre entre lengua y lengua, esa dislocación que cuestiona el poder absoluto de una gramática de legislar sobre el intelecto, y ese lugar aparece - me atrevo a decir- en el acto de traducir. No será la simple comparación entre lenguas la que hará aparecer la dislocación sino el deseo de hallar un sustituto para ciertas expresiones singulares, idiomáticas o bien acústicas. Él pondrá de manifiesto la condición de traducible (o intraducible, que para el caso es lo mismo) de las lenguas.'

Un ejemplo nos proporciona uno de esos problemas pronosticados por Nietzsche: el traductor de Heidegger sustituyó - directamente- sprache con la voz "lenguaje en general," reiniciando una "mitología filosófica." Es sabido que el término alemán permite pensar tanto lenguaje como lengua o palabra o habla o discurso, incluso como lo dicho por oposición a un decir. Sorprendentemente, sprache parece decir casi lo mismo que logos en griego y esta situación, como sabemos, no le pasó desapercibida a Heidegger, sino que de hecho sería el centro de intuiciones portentosas. ${ }^{2}$ EI traductor al español, por su parte, hizo lo que cualquiera en su caso hubiera hecho: traducir de una lengua a otra y traducir lo más directamente posible, es decir lo más técnicamente posible. Esta es una norma para todo acto de traducción. ${ }^{3}$ La decisión tomada por el traductor sin embargo resultó muy comprometida. Primero porque no daba cuenta de la polisemia técnica del vocablo alemán y segundo porque al no dar cuenta de ello ocultaba que la confusión o complicación semántica (deconstructiva) introducida con esa palabra bien podría ser propositiva. El pensar auténtico según Heidegger se propone decir en alemán lo que en griego se habría abierto al pensamiento sin decirse directamente. La relación entre el griego y el alemán no será regida por la filología ni 
por la etimología, es decir, por ninguna disciplina normativa: esta relación pretende ir mucho más allá de la técnica (etimológica o hermenéutica, por ejemplo) e implica una idea muy concreta de la traducción entre lenguas, de su posibilidad o de su necesidad. Esta no será la primera vez que la filosofía recurre a la fuerza probatoria de la traducción para dar algo en qué pensar. $Y$ aunque pensar no sea inmediatamente traducir, todo acto de pensamiento comienza como traducción, como un ejercicio que lleva fuera de uno mismo, fuera de la voluntad de decir tan típicamente humana, que renuncia al cogito, a la posibilidad del regreso seguro a la conciencia, a lo propio. El traductor sabe que no tiene nada propio que decir y que su voluntad debe servir - no a un autor, a un texto, a una lengua - sino a las artes, a las reglas de un hacer, a una técnica. Su musa es tejné.

Se dirá que la tarea que aguarda al traductor es un poco más y un poco menos que un saber: está limitada por un cierto número de obstáculos o reglas, como cualquier disciplina, está incluso institucionalizada, posee una larga historia; pero ni ésta ni aquélla le son útiles ante la disimetría a la que está condenado. La institución le exige comprometerse con el decir del otro, con el texto, con la otra lengua y la propia, y lo deja sin embargo un tanto desarmado. El traductor siempre debe decidir por sí mismo si ha cumplido con su responsabilidad. El traductor siempre ha de poner en claro el original. No se trata de la claridad de la cual solía hablar Descartes, ni tampoco la claridad solicitada en nuestros días por Hjemslev; es una claridad que el traductor se siente incapaz de abandonar y que nunca se está seguro de cumplir. Es la claridad exigida al intermediario, al medio, al instrumento: es la condena que asociamos a la técnica. La traducción trata al texto como una intertextualidad, no como una cosa acabada, a la mano y devuelve en su lugar (¿pero hay lugar de la intertextualidad?) algo que, sin ser definitivo, está siempre demasiado acabado y circunscrito por unas formas, unas maneras, una temporalidad, una circunstancia.

Sabemos lo difícil de la tarea; Walter Benjamin había advertido que el traductor suele fallar en esta empresa - puesto que le falla al otro tanto como al original (en su libertad de decirlo todo)-, que quizás, como ninguna otra que aproxima el trabajo de la lengua al del pensamiento, está marcada profundamente por una imposibilidad (1999). Mientras la traducción directa (de sonidos o idiomática) es imposible en sentido absoluto, el sentido o la significación, la comprensión y la interpretación serán siempre posibles, en un mismo sentido absoluto. La máxima semiótica, "todo significa" (Eco), ejemplifica esta creencia contemporánea. La imposibilidad no es una renuncia a la traducción, por el contrario, es un llamado urgente a repensar las reglas de la traducción, es decir, a reflexionar en su dimensión técnica como algo distinto, aunque no opuesto, de la interpretación. Este es, pues, el tema que va más allá de lo romántico y que aquí querría emprender.

Decíamos entonces que la traducción falla de manera muy determinada: no reproduce un original quizás porque no tenemos una idea exacta de lo que es el original (un sentido, una intención de autor, de significado; intención de decir de la lengua, ¿cuál de todos ellos o todos ellos juntos?). Tampoco interpreta o comprende un texto. El trabajo del traductor es un trabajo de extranjería que da entrada a lo desacostumbrado, que no 
renuncia al pensamiento y que por ende es cauteloso, vigilante; nada pues que podamos asociar con lo mecánico. Sin embargo, a la traducción le pertenece una cierta dimensión técnica. Decimos, por ejemplo, que se puede enseñar a traducir, lo que implica que se puede dar con un cierto número de reglas generales aplicables a casos singulares. Además de ser técnica en este sentido, la traducción lo es también en un sentido muy griego - como lo recordaría Heidegger, la traducción es un hacer e implica atenerse a ciertos instrumentos léxicos, diccionarios por sólo citar unos.

El camino del pensar, como la traducción a la que se parece extraordinariamente, si bien empieza en casa (por así decirlo) conduce hacia afuera, debe abandonar, como lo demandaba Nietzsche, la nación de los padres, su lengua, su religión y sus costumbres, para lanzarse en busca de un destino angustioso (por desacostumbrado) pero necesario para la verdad. La verdad surge como trabajo del pensar que se encamina, que se halla en camino hacia otra lengua, y que se coloca en situación de extranjero. Fremd que en alemán nombra al extranjero procede del alto alemán, que como bien sabía Heidegger era una lengua difícilmente usada en su día, ${ }^{4}$ en la cual significa el que sale, el que abre un nuevo sentido, un nuevo camino. Todo nuevo sentido o dirección del pensamiento requiere una cierta extranjería, una actitud distanciada, necesita, en fin, a su extranjero. Es aquí donde el pensamiento se vincula nuevamente a la traducción. (Recordemos hasta aquí que esos vínculos que ligan a una con el otro están en la claridad, la verdad y la falla). Se deshace uno de la lengua nacional donde en efecto vive y actúa, se relaciona con los otros, percibe, siente, sufre y goza; en suma, realiza y consuma lo que le es propio, aunque sea de forma imaginaria, para lanzarse en brazos de una lengua ajena. Esa extranjera con grandes poderes de seducción habría de ser la lengua griega para Heidegger y el griego y el latín para Nietzsche. Sólo en la relación de distinción (distinctio) entre la lengua materna y una otra, el griego o el latín, el pensamiento se enfrenta a su Otro: lo dicho, que lo reduce, lo solidifica, lo recluye en reglas, en órdenes discursivos, en la temporalidad.

Humboldt ya había supuesto que la comparación y la distinción entre las diferentes lenguas, mediante la traducción, llevaría a consumar todo lo posibilitado en el lenguaje en general. Abstracto como es este último término, Humboldt parecía materializarlo, concretizarlo en la actividad de la traducción $y$, en vista de que toda traducción es contingente, relativa, la consumación del lenguaje en general quedaría vinculada a las exigencias de la historia, al igual que la primera. Humboldt no estaba interesado en reconocer los problemas de idiomaticidad (lugares donde se evidencia lo singular, lo intraducible) que podrian ocurrir porque, pese a ellos, el lenguaje realizaría su finalidad ontológica: decir lo humano (general) más allá de lo nacional (particular, lo dicho también) pero a través de lo nacional o idiomático (singular). Heidegger, pese a sus críticas a Humboldt, no parece haber dejado de caminar por una senda del pensar que el segundo abriera para la reflexión alemana (y para un cierto romanticismo o modernidad).

Es sabido que Benjamin en "La tarea del traductor" sostuvo que la traducción es una actividad que liga dos lenguas y no dos intenciones de decir. De hecho, sólo el autor del texto original posee una intención o expresa un querer decir - que no siempre puede 
ser totalmente representado en lo dicho de su texto-, pero el traductor se limita a dar un sucedáneo del texto, es decir, de lo dicho. ¿No habria entonces manera de traducir, transculturizar el acto de decir, aquello que rodea la enunciación además de traducir lo enunciado? Benjamin afirma una ausencia que no nos gusta (hoy que somos postestructuralistas): ausencia de ese personaje central que es el querer decir del autor. Hace algo más: al dejar fuera el tema del querer-decir echa luz sobre una actividad que permanecía a la sombra de la significación: la actividad propiamente dicha de la traducción, no como sucedáneo sino como suceso central del lenguaje. Esta actividad es eminentemente técnica, es un hacer. Ello quiere decir en principio instrumental, es decir, es un medio para una finalidad que sería hacer comprensible un texto ajeno. Pero además es técnica porque posee reglas y éstas, como sabemos, no son trascendentales como las leyes; son contingentes, pueden ser cambiadas y requieren consensos, instituciones para ser instituidas y establecidas. Lo técnico también se dice de la aplicación de la generalidad de la regla al caso particular.

Parece que estuviéramos otra vez fuera del campo de la pura traducción, ocupándonos de otros asuntos cuando en realidad estamos en el corazón de la actividad misma. Lo técnico, sabemos, introduce cambios importantes en las formas del hacer y de pensar esa actividad. La traducción sometida al embate de lo técnico no tiene más remedio que replantearse el problema de su exterior: la relación con el otro, el autor y la otra lengua, la otra nación y, por qué no, la historia otra, la del otro. Y no es que quede fuera el querer decir del autor, es que siempre nos es exterior y sólo podemos acercarnos tomando ciertas decisiones, es decir, no satisfaciendo reglas sino cuestionándolas o saltándolas.

En el instante cuando lo técnico penetra lo humano, ya no hay escape; pero lejos de ser una condena podría ser una salvación. La dimensión técnica de la traducción no impone a ésta el ser un medio para una finalidad exterior, un decir ajeno. El hacer (técnico) de la traducción posee una cierta materialidad que Benjamin había expresado de forma negativa como un hacer fallido, como un hacer que se sabe enfermo, es decir, como una suerte de pathos de la distancia. Pathos moderno, ya sea nostálgico o melancólico. Hay otra clase de materialidad que Benjamin dejó sin formular; se asemeja a esa materialidad de la mano cuando debe acoplar su naturaleza a la del lápiz, la pluma, la máquina de escribir, y al hacerlo se transforma a sí misma y ensaya nuevas maneras - formas desacostumbradas - para hacer hablar al lápiz, a la pluma o al tablero de la computadora. Sí, en efecto es un padecimiento, cuesta trabajo, exige una fuerza determinada, pero a la vez es un acto de libertad. 


\section{Notas}

'Lo intraducible es, por ejemplo, lo que llamamos expresiones idiomáticas, incrustadas en la vida misma de una lengua nacional, un dialecto, etcétera, en lo local y absolutamente singular.

${ }^{2}$ Imposibilidad de traducir logos a partir de su genealogía latina que estableció -equivocadamente, según Heidegger-la sinonimia entre logos y ratio. Algo similar ocurrió, sostiene el filósofo alemán, con la expresión griega hipokeimenon y su genealogía latina a partir de la raíz semántica de sujeto (Heidegger 1991, 54-68).

${ }^{3}$ Aquí asoma el tema, que trataré a continuación, el de la técnica. Esta no sólo significa instrumentalidad o un hacer, significa también el automático paso de la regla - la norma al caso específico, automatismo o mecanicismo que no da lugar a la reflexión. No habria puesta en cuestión de la regla ni posibilidad ni necesidad de cambiarla por otra mejor.

${ }^{4}$ Esto tiene su importancia. Nietzsche y Heidegger confrontan su lengua viva con una lengua en la que ya no se escriben textos ni tampoco se habla, con una lengua que parece haber perdido la capacidad de decir lo nuevo, absolutamente nuevo. Derrida, por el contrario, recurre a la diferencia entre lenguas vivas, es decir poieticamente activas.

\section{Obras citadas}

Benjamin, Waiter. 1999. "La tarea del traductor." Ensayos escogidos. México: Ediciones Coyoacán.

Heidegger, Martin. 1991. "La pregunta por la técnica." Revista Crítica I: 54-68. Valverde, José Ma. 1994. Nietzsche de filólogo a Anticristo. Barcelona: Planeta. Kleist, Heinrich von. 1995. "Sobre la paulatina elaboración de los pensamientos al hablar.” Ensayistas alemanes. México: Conaculta. 175-80. 